\title{
Research
}

\section{Experiences of carers managing childhood eczema and their views on its treatment:}

\author{
a qualitative study
}

\begin{abstract}
\section{Background}

Childhood eczema causes significant impact on quality of life for some families, yet nonconcordance with treatment is common.

\section{Aim}

To explore parents' and carers' views of childhood
\end{abstract} eczema and its treatment.

\section{Design and setting}

Qualitative interview study in primary care in the south of England.

\section{Method}

Carers of children aged $\leq 5$ years with a recorded diagnosis of eczema, who reported that eczema was still a problem, were invited to participate. Thirty-one parents were interviewed from 28 families.

\section{Results}

Many parents expressed frustration with both medical care and prescribed treatments. They felt their child's suffering was not 'taken seriously', and experienced messages about a 'trial and error' prescribing approach and assurance that their child would 'grow out of it as a further 'fobbing off', or dismissal. Many carers were ambivalent about eczema treatments, mainly topical corticosteroids but also emollients. Dietary exclusions as a potential cure were of interest to most families, although they perceived healthcare professionals as uninterested in this. Families varied in the extent to which they felt able to manage eczema and the length of time taken to gain control. In some instances, this was linked to not understanding advice or receiving conflicting advice from different healthcare providers.

\section{Conclusion}

Poor concordance with treatments seems unsurprising in the presence of such dissonance between carers' and healthcare providers agendas. Acknowledging the impact of the condition, greater attention to how key messages are delivered and addressing carers' treatment beliefs are likely to improve engagement with effective self-care.

\section{Keywords}

atopic dermatitis; child; eczema; medication adherence; primary health care; qualitative research.

\section{INTRODUCTION}

Childhood eczema is very common, affecting over $20 \%$ of children aged $\leq 5$ years at some point. ${ }^{1}$ Skin complaints are the second most common reason for GP consultation, after infectious illness, in children aged $\leq 5$ years. ${ }^{2}$ Eczema can cause significant distress to the child and family due to sleep disturbance and itch. ${ }^{3,4}$ In the majority of cases, eczema starts before the age of 4 years, ${ }^{5}$ and clears by the teenage years, although relapses may occur. ${ }^{6}$ In the intervening years, and for those in whom the eczema persists, it can be viewed as a long-term condition, as both the impact of the condition and application of treatments place a substantial burden on carers. Research from secondary care suggests that, in terms of the impact on quality of life in children, generalised eczema is second only to cerebral palsy, with greater impact reported than for asthma or diabetes.?

The major cause of treatment failure in childhood eczema is poor adherence arising for a number of reasons, including poor understanding of topical preparations, fear of side effects of topical corticosteroids, child refusal of therapy, or therapy being too time consuming. ${ }^{8}$ The National Institute for Health and Clinical Excellence (NICE) guideline on atopic eczema in children concluded that lack of education about

M Santer, MSc, PhD, MRCGP, clinical research fellow; H Burgess, BM, BSc (Hons), academic clinical fellow, Primary Medical Care, Aldermoor Health Centre; L Yardley, PhD, professor of health psychology; I Muller, MSc, research assistant, Psychology; C Hugh, medical student; P Little MSc, MD, MRCP, FRCGP professor in primary care research, Primary Care and Population Science, University of Southampton,

Southampton. S Ersser, BSc (Hons), PhD, RGN CertTHEd, professor of nursing and dermatology care and dean, Faculty of Health and Social Care, University of Hull, Hull. S Lewis-Jones, FRCP, FRCPH, honorary consultant dermatologist and honorary clinical lecturer, Ninewells Hospital and therapy leads to poor adherence, and consequently to treatment failure. ${ }^{9} \mathrm{~A}$ recent Cochrane review found that most studies of parental education for childhood eczema have been small or of poor quality, and lacking in theoretical underpinning, ${ }_{10}^{10}$ but structured parental education for eczema can improve outcomes in a trial setting. ${ }^{11}$ Improved early control of eczema may lead to improved prognosis of eczema, and may also be linked to improvement in other atopic conditions such as asthma, rhinitis, and food allergy. ${ }^{12}$ Encouraging patients and carers to take an active role in their health care may also improve their use of health services. ${ }^{13}$

A first step in addressing adherence is to understand carers' current beliefs around childhood eczema and what they understand about its diagnosis, prognosis, and treatment. This qualitative study was carried out with carers of children with eczema, to explore their views and experiences of the condition and its management.

\section{METHOD}

\section{Participants}

Parents or carers of children aged $\leq 5$ years, who had consulted with eczema, were invited to participate by GP letter addressed to 'parent or carer of [name of child]'. They

University of Dundee, Dundee. Address for correspondence Miriam Santer, Primary Medical Care, University of Southampton, Aldermoor Health Centre, Aldermoor Close, Southampton, S016 5ST.

E-mail: m.santerasoton.ac.uk

Submitted: 9 November 2011; Editor's response: 18 November 2011; final acceptance: 28 November 2011.

@British Journal of General Practice This is the full-length article (published online 26 Mar 2012) of an abridged version published in print. Cite this article as: Br J Gen Pract 2012; DOI: 10.3399/bjgp12X636083. 


\section{How this fits in \\ Childhood eczema is common and can have a substantial impact on quality of life for families, mainly due to sleep disturbance and distress from itching and scratching. The main cause of treatment failure is known to be non-concordance with the use of prescribed treatments. This study found that some carers are cautious about the use of emollients as well as topical corticosteroids and dislike the 'trial and error' approach to prescribing. Carers have a strong interest in exploring diet and allergy as a potential cure for eczema, which they perceive as not shared by their healthcare provider. It is unsurprising that carers do not adhere to prescribed treatments, given the mismatch in agendas between carers and their healthcare providers.}

were asked to return a reply slip to the research team and, if they indicated that they would like to participate and that their child's eczema was still a problem, they were phoned to arrange an interview.

Participants were from practices in Southampton City (two practices), Hampshire lone in Havant and one in Emsworth), and Dorset (two practices in Poole). Participants were recruited from three practices initially, then from three more, in order to obtain sufficient numbers. An attempt was made to obtain diversity of participants through recruiting from practices in varying sociodemographic areas. Interviews were conducted in participants' homes, except for one who preferred to be interviewed at her general practice. Interviews were carried out by three researchers between December 2010 and May 2011. Each interview lasted

\section{Table 1. Participant characteristics}

\begin{tabular}{|c|c|}
\hline Participant characteristic & Description \\
\hline Interviewees relationship to child & 24 mothers, 1 father, 3 parents interviewed together \\
\hline Interviewees age & Median 36 years (range $26-46$ years) \\
\hline Age of most affected child & Median 3 years (range 7 months -5 years) \\
\hline $\begin{array}{l}\text { Eczema severity } \\
\text { (parent asked if mild, moderate, or severe) }\end{array}$ & 16 mild, 10 moderate, 2 severe \\
\hline Consulting history & $\begin{array}{l}14 \text { GP only, } 5 \text { dermatology nurse, } 9 \text { dermatology, } \\
\text { and/or allergy clinic }\end{array}$ \\
\hline Family structure & $\begin{array}{l}\text { Median number of children in household } 2 \text { (range } 1 \\
\text { to 4); } 27 \text { households with both parents, } 1 \text { household } \\
\text { with mother only }\end{array}$ \\
\hline Interviewees' employment status ${ }^{a}$ & $\begin{array}{l}14 \text { full-time carers; } 8 \text { professional; } 8 \text { other such as } \\
\text { admin or retail; } 1 \text { student }\end{array}$ \\
\hline Ethnicity & $\begin{array}{l}25 \text { white British; } 3 \text { black or Asian British; } 2 \text { white } \\
\text { non-British; one mixed heritage British }\end{array}$ \\
\hline
\end{tabular}

between 30 and 60 minutes. Interviews were audiorecorded, transcribed, checked, and assigned pseudonyms.

\section{Interviews}

Interviews were semi-structured, using an interview guide developed by three of the researchers. The interview guide started with the open question, 'Can you tell me a bit about your child's eczema to start with?', with prompts for history of the eczema; impact of eczema on the child and the family; all information they had received about eczema and where this had been obtained (including internet and leaflets); and how they managed the eczema and any barriers encountered to this.

\section{Analysis}

Analysis was carried out thematically and iteratively using a constant comparative approach. ${ }^{14} \mathrm{~A}$ coding frame was developed by three researchers, based on data from the first 10 transcripts, and was further refined based on subsequent transcripts. Two of these researchers coded the data and resolved queries through discussion. Data saturation was achieved for all major codes. Clusters of codes were developed into themes, and relationships between themes were analysed once data collection was complete. Counter examples were sought for each theme and, although these are not always presented, it is indicated in the text where themes were pertinent to all, to the majority, or to a few of the responders. QSR NVivo 9 facilitated the coding and organisation of data.

\section{RESULTS}

\section{Participants}

Invitations were sent to 289 households; 70 replies (24\%) were received, of which 33 said eczema was no longer a problem, three declined for other reasons and six were not contactable, resulting in 28 interviews $10 \%$ of mail-out). Participant characteristics are shown in Table 1.

\section{Findings}

Parents described considerable impact on their child from eczema, particularly due to itching, scratching, and sleep disturbance. The severity of impact varied widely; some families altered activities Isuch as swimming, going to the beach, contact with pets or animals), or worried about their child's future, for instance regarding appearance, bullying and, in a few cases, socialisation and development. There was widespread caution around the use of topical corticosteroids. These findings are 
common to previous research, so this paper focuses on newer insights that relate to self-care for childhood eczema. Carers' responses to the medical model of management of childhood eczema (Table 2) were explored, then difficulties arising in their interactions with their healthcare providers around eczema were examined.

\section{Emollients}

There is widespread medical consensus that emollients are the mainstay of eczema treatment, yet some families were reluctant to use them, either because they felt they didn't work, or through seeing emollients as 'unnatural' or potentially harmful in the long term. There were mixed feelings about the process of 'trial and error', a process that is often necessary to find an emollient that suits the child. While some families accepted that different preparations might suit different children, others experienced this as a further indication of being 'fobbed off' or dismissed by their healthcare provider:

'Some of the creams, obviouslyyou can read the label but you don't know everything that's in it and you kind of think - I'm not into kind of putting loads of chemicals on them if I can possibly avoid it, which is why I think in the end my solution was if it's really bad I'll use the cream but otherwise l'll just stay away from anything I put on his skin and look at diet first and then kind of consider that.' (Helen)

I don't really like putting creams on them, because I don't agree with that sort of thing, you know if you've got a headache have a

\section{Table 2. Carers' views of the medical management of childhood eczema}

\section{NICE guideline on atopic}

\section{eczema in children -}

key recommendations

Emollients should always be used,

even when the atopic eczema

is clear

\section{Examples of carers' view of medical management}

IIt's not like asthma when my husband takes a brown puff inhaler every day just to keep it going rather than just when an attack happens; whether that's right or wrong, I don't know, but I'm thinking of the long-term, cumulative impact of constantly slapping all this stuff on [emollients] and your skin is a sponge, and it's just absorbing it and going into the bloodstream, I think, well, it's probably better off if their skin can naturally deal with whatever's going on at the time ...' (Kim)

Treatment should be stepped up to topical corticosteroids for flare-ups

My mum has got a friend who has used all her life and her skin is pretty - you get that sort of scarring don't you, she's got that on her face, so that's sort of long-term use I know but I'm always thinking about it when I'm applying it. '(Vicky)

Allergy testing is not helpful I would hope that they would do a little bit more tests as to find out in eczema suddenly flare up or you know what they eat food wise ... (Sabrina)

drink of water and go to sleep ... So I would prefer not to "guinea pig" them and "let's see if this cream works". (Val)

\section{Topical corticosteroids}

As in previous studies, ${ }^{4}$ most parents were cautious about using topical corticosteroids and were concerned about possible side effects from applying them to their child's skin. In four families this was exacerbated by apparently having received conflicting advice from different healthcare providers regarding topical corticosteroids, heightening their concerns and delaying their ability to gain control of the eczema:

And I know at one stage, one GP said no, Elocon $^{\circledR}$ 's [mometasone furoate] too strong, don't use that. And then I went back to my other GP because without using Elocon, I couldn't seem to get to that stage where I could maintain it and that GP was like, "no, have the Elocon"... It's hard isn't it, when you get conflicting advice and then it was even harder when actually I took their advice and then it was not managed well, do you know what I mean? Cause not using the Elocon when it's bad, just doesn't work.' (Sarah)

Four other families were confused about the advice they had received regarding topical corticosteroids and this may also have increased their caution:

Interviewer: 'And you mentioned they [dermatology clinic] gave you a couple of steroid creams, how do you feel about those?"

Sam: 'When they are really, really bad, obviously I use them, but I don't like using them all the time; yeah, he gave me one for the face, cause he has it all round his lips as well, which is not very nice for him. He's got it now, actually, round his lips and one for his body, but I don't know which one is which; because obviously, I've got so many creams ... I haven't got a clue.'

\section{Diet and allergy}

Dietary changes are not routinely recommended in eczema but were mentioned by 21 of the 28 interviewees. Five of these had children who were on exclusion diets for other allergies. Of the remainder, most had made or were making changes without discussion with a healthcare practitioner. Four families had tried food exclusions but found them either of no benefit or too difficult to continue with:

'She's got a very limited diet. She eats lots of 
cheese, we did try and take the cheese away thinking that maybe it was a dairy thing not worth it, she then refused to eat absolutely anything at all.' (Val)

A range of food exclusions had been tried, including dairy, eggs, chocolate, food additives, kiwi fruits, and tomatoes. One mother excluded all coloured foods from her baby's diet. Families were unsure about dietary manipulation and felt more professional input would have been welcome:

Interviewer: And what do you feel you would get out of having a regular review? [Amy had raised that she would welcome this]

Amy: Well, I think I would know more whether I still need to persist doing things or not ... I feel that it was never fully explored if diet was a big factor in it; that was one of the things that I was haphazardly doing myself, which I do think has a big impact, and I do think, because she switched to soya, that's probably had some help now...

Although parents were often interested in dietary changes, they said that their doctors were not. Helen is representative of many parents with an interest in dietary allergens, in that, although she is interested in whether they are responsible for her child's eczema, she does not seem to have asked her doctors about this:

"I think doctors very much kind of say, "Oh well, here's the cream", and, you know. "That'll do, don't come back and bother me". I think, unfortunately, that's ... that's the impression I have because it's not often people sit and say, "Well, you know, what has he been eating?".' (Helen)

\section{Perceptions of doctors}

Many interviewees felt that their GP did not take the condition as seriously as they would have liked. There were exceptions to this: a few had found their GP very supportive; a few focused their dissatisfaction on secondary care rather than primary care; some parents who had eczema themselves did not seem to feel a need for support from the GP beyond being a source of repeat prescriptions. Harry and Julia are typical of those who felt more should be done to help their child:

'But it depends which doctor you see; some doctors think it's not necessary and some doctors think - they prescribe you something else. But the one that we saw yesterday thought it wasn't necessary, but we thought it was. It just depends.

Because maybe - to them - they've seen worse, seen worse cases of eczema, but to us, she's still not well, if it's stopping her - if it's limiting her daily life, it's worse for her and she deserves something different or to try something.' (Harry and Julia)

Some parents seemed to experience their doctors' assurances that their child would 'grow out of' eczema, as dismissive of its current impact:

And then it got to the point where my mother actually took her in because I was getting nowhere with the doctor, he kept on fobbing me off with rubbish, you know, "She'll grow out of it", yeah but that doesn't help now, and I was talking to my mother about it one day and she went, "Right I will take her in". So she took her in and she argued with him. D [husband] has taken her in and it just doesn't make any difference, they are not interested. Childhood eczema, to them is not a problem, they have got bigger and more worrying things to worry about, probably.' (Val)

Parents who spoke about having been offered a review were generally more positive about the ongoing relationship with healthcare professionals in managing their child's eczema. Others said they would have welcomed a review:

So they [GPs] were very good, very helpful and they all said, you know, come back if it gets worse or it doesn't clear up and they will try other things, and I have gone back a few times and been given various treatments to try and some have been good and some haven't. It's just trial and error, obviously, with each child and each case of eczema.' (Julie)

When she was suspected of being a bit asthma-y, which was nowhere near as big an effect on us, there were all different things, we were being called every year for an asthma check and different things, but I think, in some ways, it's not reviewed and checked, it's only me going in and asking for stuff or getting repeat prescriptions, it doesn't seem to be that it's something that's monitored. It's only me going in and saying this is really bad, can I have something else for it now when it flares up.' (Amy)

\section{Difficulties in the relationship with the} healthcare provider

A frustration for some parents was that they were seeking a 'cure' for their child's 
eczema, for instance through allergy testing, whereas doctors, in line with national guidelines, were seeking to 'control' eczema, mainly through emollient therapy:

I think he [GP] could have done like a patch test, you know, a lot of people have said that he could do a patch test to find out - to get to the bottom of what it is, cos at the end of the day, I have got two kids and it's hard work having to cope with a little boy with that. So he could have given me a bit more help, I think, anyway, not just bung more creams, because it's just not working.' (Sam)

In common with other studies, 15,16 his study found that parents can feel that others are making negative judgements of their parenting if eczema affects their child's appearance. In addition, a few of the interviewees also felt judged by their healthcare provider and were upset and angry about this:

Interviewer: And have you been to the GP about it [baby's eczema]?'

Fazeela: 'I have and it's just the same story .. "Are you moisturising?" It's a question that is just like, to me, now, it's a really stupid question [raising voice]; it's not something I want to watch, to watch a child taking chunks of skin out in their hand with big red patches of blood ... actually, it's distressing when you take the clothes off in front of a GP or a health visitor and they look. I find it, I get quite upset cause they're looking at it and they're like, "It's very dry". It's a stupid question, "Are you moisturising?" Well yes, I am. Why would I want my child to go through that? That's what frustrates me I think, is the fact that they are quick to criticise when they are not really helping me at the moment.

Some interviewees had received conflicting advice or not understood advice they had received about treatments, as discussed above, and this may have delayed the process of gaining control of the eczema. Others described gaining control as a lengthy process, and some were clear in linking their delay in achieving control with the type of care they had received:

I kind of feel that ... and it is a case of - they send it away with you, it's not come back in, say, 2 months' time and we'll review whether it's making a difference or not ... I have felt some of the time that I'm making it up as / go along. But it's been [since] going to the allergy clinic and that, I felt that kind of ... we eventually got round to how it is now and what we use seems to do the trick, but really, it's taken us probably over a year to get to that point and obviously it would have been nice to have got to that point a bit earlier.' (Nicky)

\section{DISCUSSION}

\section{Summary}

This qualitative study found that carers commonly feel unsupported in caring for their child's eczema. They often perceive healthcare providers as not taking it seriously', and experience messages, for instance, that their child will 'grow out of it' or around a 'trial and error' approach to prescribing, as a further 'fobbing off', or dismissal. Furthermore, there are conceptual differences around eczema treatments between healthcare providers and carers, who may view the most commonly prescribed treatments (emollients and topical corticosteroids) with caution. Carers often perceive doctors as being uninterested in the one aspect of treatment that they think may offer a hope of 'cure', for example, diet and allergy. Experiences of conflicting advice or not understanding advice may have delayed the process of gaining control of the eczema for some.

\section{Strengths and limitations}

The low response rate may mean that the interviewees in this study are not representative of other families, but saturation of major codes and the broad range of views and experiences found here are reassuring. Triangulation was not possible within this study, although the findings are congruent with those of other studies. Certain groups are underrepresented, for instance fathers and single parents, but the time pressures experienced by carers of young children contribute to their being difficult to contact. A further limitation of the study is that many of the findings pertain to the perceived mismatch in carers' and doctors' agendas, yet the view of the doctors involved have not been sought.

\section{Comparison with existing literature}

Previous qualitative work, carried out among predominantly secondary care populations, has described similar findings regarding the impact of childhood eczema on family life and carers' unease around topical corticosteroids. ${ }^{15-18}$ The present study shows that these issues are also pertinent to the milder case mix seen in 
primary care, where the vast majority of cases are managed. Qualitative studies in other healthcare settings have found accounts of carers feeling that doctors do not take eczema seriously and that they offer insufficient information. ${ }^{19,20}$ However, the present study goes further in exploring carers' perceptions of the medical management of eczema and how their agendas may differ from those of their doctors.

\section{Implications for practice and research}

Carers wish to feel that the impact of the condition is acknowledged and the considerable efforts they make towards self-care are understood. Plausible explanations are needed to build concordance with treatment goals, and if explanations are at odds with carers' beliefs then these need to be addressed. In the context of childhood eczema, this includes being prepared to discuss diet and allergy explicitly, explaining the rationale behind regular emollients, and offering clarity about the safe use of topical corticosteroids.

The families interviewed here had modest requests - for GPs within one practice to be consistent in the advice they offer regarding topical corticosteroids, and for carers to be actively offered permission to return if necessary. The NICE guideline on atopic eczema in children suggests that treatment for childhood eczema should be reviewed at least once a year, and the present findings suggest that many carers would welcome this. It may be that if carers feel more positive about the support from their healthcare provider, they will feel more able to self-care, especially if pointed towards good-quality self help materials. 


\section{REFERENCES}

1. Williams HC, Stewart A, von Mutius E, et al, and the International Study of Asthma and Allergies in Childhood (ISAAC) phase one and three study groups. Is eczema really on the increase worldwide? J Allergy Clin Immunol 2008; 121(4): 947-954.

2. Royal College of General Practitioners, OPCS DoH. 4th National morbidity statistics from general practice 1991-1992. London: HMSO, 1995

3. Lewis-Jones MS, Finlay AY. The Children's Dermatology Life Quality Index (CDLQI): initial validation and practical use. $\mathrm{Br} J$ Dermatol 1995; 132(6): 942-949.

4. Zuberbier T, Orlow SJ, Paller AS, et al. Patient perspectives on the management of atopic dermatitis. J Allergy Clin Immunol 2006; 118(1): 226-232

5. Kurukulaaratchy R, Fenn M, Matthews S, et al. The prevalence, characteristics of and early life risk factors for eczema in 10-year-old children. Pediatr Allergy Immunol 2003; 14(3): 178-183.

6. Williams HC, Strachan DP. The natural history of childhood eczema: observations from the British 1958 birth cohort study. Br J Dermatol 1998; 139(5): 834-839.

7. Beattie PE, Lewis-Jones MS. A Comparative study of impairment of quality of life (QoL) in children with skin disease and children with other chronic childhood diseases. Br J Dermatol 2006; 155(1): 145-151.

8. Beattie PE, Lewis-Jones MS. Parental knowledge of topical therapies in the treatment of childhood atopic dermatitis. Clin Exp Dermatol 2003; 28: 549-53.

9. National Institute for Health and Clinical Excellence. Atopic eczema in children. CG57. London: National Institute for Health and Clinical Excellence, 2007. http://www.nice.org.uk/nicemedia/pdf/CG057FullGuideline.pdf laccessed 7 Mar 2012).
10. Ersser SJ, Latter S, Sibley A, et al. Psychological and educational interventions for atopic eczema in children. Cochrane Database Syst Rev 2007; (3): CD004054.

11. Staab D, Diepgen $T L$, Fartasch $M$, et al. Age related structured educational programmes for the management of atopic dermatitis in children and adolescents:multicentre, randomised controlled trial. BMJ 2006; 332: 933-936.

12. Van den Oord RA, Sheikh A. Filaggrin gene defects and risk of developing allergic sensitisation and allergic disorders: systematic review and metaanalysis. BMJ 2009; 339: b2433.

13. Coulter A, Ellins J. Effectiveness of strategies for informing, educating and involving patients. BMJ 2007; 335(7609): 24-27.

14. Seale C. The quality of qualitative research. London: Sage, 1999.

15. Chamlin SL, Frieden IJ, Williams ML, Chren M. Effects of atopic dermatitis on young American children and their families. Pediatrics 2004; 114(3): 607-611.

16. McKenna SP, Whalley D, Dewar AL, et al. International development of the Parents' Index of Quality of Life in Atopic Dermatitis (PIQoL-AD). Qual Life Res 2005; 14(1): 231-241.

17. Elliott BE, Luker K. The experiences of mothers caring for a child with severe atopic eczema. J Clin Nurs 1997; 6: 241-247.

18. Lawson V, Lewis-Jones MS, Finlay AY, et al. The family impact of childhood atopic dermatitis: the Dermatitis Family Impact questionnaire. $\mathrm{Br} J$ Dermatol 1998; 138: 107-113

19. Gore C, Johnson RJ, Caress AL, et al. The information needs and preferred roles in treatment decision-making of parents caring for infants with atopic dermatitis: a qualitative study. Allergy 2005; 60(7): 938-943.

20. Noerreslet M, Jemec GB, Traulsen JM. Involuntary autonomy: patients' perceptions of physicians, conventional medicines and risks in the management of atopic dermatitis. Soc Sci Med 2009; 69(9): 1409-1415. 